\title{
Contralateral pupillary dilatation and hemiparesis: Kernohan's notch revisited
}

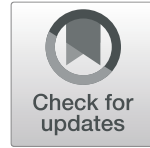

\author{
Amit Agrawal $^{1 *}$ (D) V. A. Kiran Kumar ${ }^{1}$ and Luis Rafael Moscote-Salazar ${ }^{2}$
}

\begin{abstract}
Intracranial mass lesions can lead to transtentorial uncal herniation, and pupillary asymmetry is a well-recognized sign of impending cerebral herniation. Impending uncal herniation can lead to ipsilateral, bilateral, or uncommonly the contralateral pupillary dilatation. We report a case of a 22-year old, who had contralateral pupillary dilatation due to expanding intracranial mass lesion and recovered well after neurosurgical intervention. This case illustrates contralateral pupillary dilatation ("false-localizing" sign) in a sub-group of patients, and if untreated and ICP continues to rise, this is followed by ipsilateral pupil dilatation.
\end{abstract}

Keywords: Traumatic brain injury, Cerebral herniation, Pupillary asymmetry

\section{Introduction}

Pupillary asymmetry is a well-recognized sign of impending cerebral herniation $[1,2]$. Pupillary asymmetry may be ipsilateral, bilateral $[1,2]$, or uncommonly, the contralateral pupil dilates first $[3,4]$.

\section{Case report}

A 22-year-old male skid and fell from a motorbike. He was unconscious since the time of the incident and had multiple episodes of vomiting with ear and nasal bleed. There was no history of seizures. On examination, he was afebrile, pulse rate was $87 / \mathrm{min}$, and blood pressure was $120 / 70 \mathrm{~mm} / \mathrm{Hg}$. His Glasgow coma score was E2M2V1. The right pupil was $2 \mathrm{~mm}$ reacting to light, and the left pupil was $4 \mathrm{~mm}$ sluggishly reacting (Fig. 1a). The patient was spontaneously decerebrating with paucity of movement on the left side. In view of poor GCS, he was intubated and electively ventilated. A CT scan of the brain showed thick right parieto-occipital extradural hematoma with mass effect, underlying contusion, bifrontal patchy contusions (left $>$ right), linear fracture of the right occipital bone with significant cerebral edema, mass effect, distortion, and displacement of the

\footnotetext{
* Correspondence: dramitagrawal@gmail.com; dramitagrawal@hotmail.com 'Department of Neurosurgery, Narayana Medical College Hospital,

Chinthareddypalem, Nellore, Andhra Pradesh 524003, India

Full list of author information is available at the end of the article
}

brain stem (Fig. 1b and c). His blood investigations including coagulation profile were within normal range. The patient underwent emergency right parieto-occipital craniotomy and evacuation of extradural hematoma. The patient was electively ventilated. Following the evacuation of the hematoma, the pupillary asymmetry resolved in immediate post-operative period. The patient underwent an early tracheostomy, gradually weaned off from the ventilator, and could be shifted to ward. He received regular chest and limb physiotherapy. He could be weaned off from tracheostomy and improved to GCS E4V5M6.

\section{Discussion}

Expanding intracranial mass lesions particularly those that involve the temporal lobe can lead to transtentorial uncal herniation causing direct ipsilateral oculomotor nerve compression (or stretching and torsion) and pupillary dysfunction $[1,2]$. In contrary to this contralateral pupillary dilatation ("false-localizing" sign) in a subgroup of patients [3, 4], and if untreated and ICP continues to rise, ipsilateral pupil also dilates [3-5]. Herniation of the uncus results in compression of the ipsilateral occulomotor nerve and ipsilateral pupillary dilation [1, 2]; however, if the location of the lesions is higher than the uncus, displacement and distortion of the brainstem follows which results in compression of 


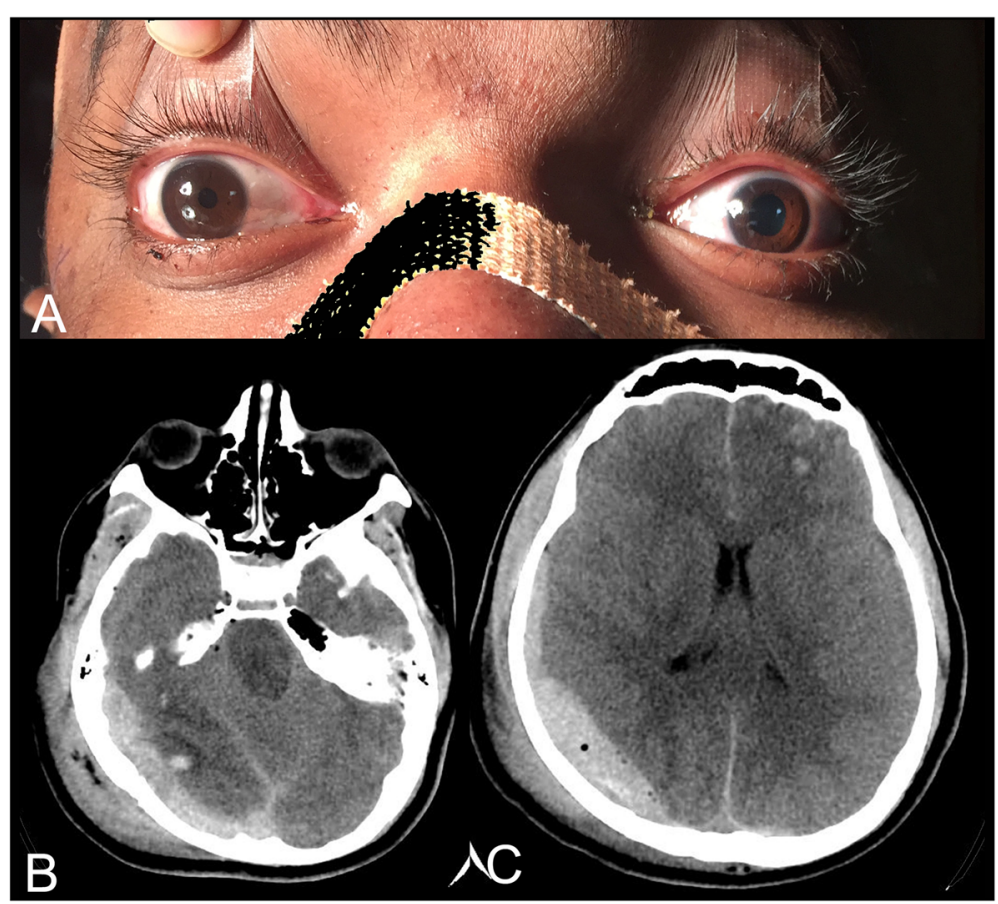

Fig. 1 a Clinical photograph showing pupillary asymmetry (left > right), left pupil was sluggishly reacting to light. b CT scan of the brain (plain) showing a large right occipito-parietal extradural hematoma, with underlying contusion (please note the compression and gross distortion of the brainstem). c Contrecoup left frontal polar patchy contusion

the contralateral cerebral peduncle and occulomotor nerve leading to opposite side pupillary dilation and hemiparesis (Kernohan's notch) [1-4].

\section{Conclusions}

This case illustrates contralateral pupillary dilatation ("false-localizing" sign) in a sub-group of patients, and if untreated and ICP continue to rise, this is followed by ipsilateral pupil dilatation.

\section{Abbreviations}

ICP: Intracranial pressure; CT: Computerized tomography

\section{Acknowledgements}

None

\section{Authors' contributions}

All the authors (AA, VAKK, LRM) have contributed to the manuscript preparation equally. The authors read and approved the final manuscript.

\section{Funding}

None

\section{Availability of data and materials}

Please contact author for data requests.

\section{Ethics approval and consent to participate}

The study was approved by Institutional Ethical Committee. This study was conducted in accordance with the fundamental principles of the Declaration of Helsinki.

\section{Consent for publication}

Written informed consent was obtained from the patient for publication of this letter to the editor and any accompanying images.
Competing interests

The authors declare that they have no competing interests.

\section{Author details}

'Department of Neurosurgery, Narayana Medical College Hospital,

Chinthareddypalem, Nellore, Andhra Pradesh 524003, India.

${ }^{2}$ Neurosurgery-Critical Care, RED LATINO, Organización Latinoamericana de

Trauma y cuidado, Neurointensivo, Bogota, Colombia.

Received: 10 May 2019 Accepted: 2 November 2020

Published online: 17 November 2020

\section{References}

1. Reid W, Cone WV. The mechanism of fixed dilatation of the pupil: resulting from ipsilateral cerebral compression. J Am Med Assoc. 1939;112:2030-4.

2. Sunderland $\mathrm{S}$. The tentorial notch and complications produced by herniations of the brain through that aperture. Br J Surg. 1958;45:422-38.

3. Chen R, Sahjpaul R, Del Maestro RF, Assis L, Young GB. Initial enlargement of the opposite pupil as a false localising sign in intraparenchymal frontal haemorrhage. J Neurol Neurosurg Psychiatry. 1994;57:1126-8.

4. Kernohan JW, Woltman HW. Incisura of the crus due to contralateral brain tumor. Arch Neurol Psychiatry. 1929;21:274-87.

5. Marshman LA, Polkey CE, Penney CC. Unilateral fixed dilation of the pupil as a false-localizing sign with intracranial hemorrhage: case report and literature review. Neurosurgery. 2001:49:1251-5 discussion 1255-1256.

\section{Publisher's Note}

Springer Nature remains neutral with regard to jurisdictional claims in published maps and institutional affiliations. 